\title{
Correlation between brain natriuretic peptide levels and the prognosis of patients with left ventricular diastolic dysfunction
}

\author{
HUI GONG ${ }^{1}$, XIN WANG $^{2}$, YI-JUN SHI ${ }^{2}$, WEN-JING SHANG ${ }^{2}$, YI LING ${ }^{2}$, LI-JIAN PAN ${ }^{2}$ and HAI-MING SHI ${ }^{1}$ \\ ${ }^{1}$ Department of Internal Medicine, Division of Cardiology, Huashan Hospital of Fudan University, Shanghai 200040; \\ ${ }^{2}$ Department of Medicine and Therapeutics, Division of Cardiology, Jinshan Hospital of Fudan University, \\ Shanghai 200540, P.R. China
}

Received October 31, 2014; Accepted January 19, 2016

DOI: $10.3892 / \mathrm{etm} .2016 .3203$

\begin{abstract}
The present study aimed to investigate the association between brain natriuretic peptide (BNP) levels and the prognosis of patients with left ventricular (LV) diastolic dysfunction. A total of 708 inpatients with cardiovascular disease (mean age, 66 years; 395 males and 313 females) were grouped according to initial BNP and were followed-up for 20-51 months (average, 30.86 months) until endpoint events occurred. Endpoints were defined as mortality or readmission due to cardiovascular disease, or mortality due to any other reason. A total of 67 and 77 events were reported in the BNP $\leq 80 \mathrm{pg} / \mathrm{ml}$ and BNP $>80 \mathrm{pg} / \mathrm{ml}$ groups, respectively. The occurrence rate of the endpoint was significantly higher in the BNP $>80 \mathrm{pg} / \mathrm{ml}$ group, as compared with the BNP $\leq 80 \mathrm{pg} / \mathrm{ml}$ group (26.28 vs. $16.14 \%$; relative risk=1.63). Furthermore, the durations of patient survival were significantly shorter in the BNP $>80 \mathrm{pg} / \mathrm{ml}$ group, as compared with the BNP $\leq 80 \mathrm{pg} / \mathrm{ml}$ group $(\mathrm{P}=0.0006)$, and patient survival decreased as $\mathrm{BNP}$ levels rose $(\mathrm{P}=0.0074)$. Among the 708 patients, 677 underwent echocardiographic detection at the same time. No significant correlation was detected between BNP levels and survival time in 178 patients with normal LV diastolic function [mitral Doppler flow, early diastolic (E)/late diastolic (A)>1] $(\mathrm{P}=0.2165)$; whereas a negative correlation was determined in 499 patients with LVD dysfunction $(\mathrm{E} / \mathrm{A} \leq 1)$ (Spearman's rho=-0.0899; $\mathrm{P}=0.0447)$. The prognoses of patients with elevated BNP levels were correspondingly worse in the present study and these correlations were demonstrated to be significant in patients with LV diastolic dysfunction. Therefore, BNP levels may be used to predict the prognosis of patients with cardiovascular disease.
\end{abstract}

Correspondence to: Professor Hai-Ming Shi, Department of Internal Medicine, Division of Cardiology, Huashan Hospital of Fudan University, 138 Yixueyuan Road, Shanghai 200040, P.R. China

E-mail: haimingshicn@126.com

Key words: brain natriuretic peptide, diastolic dysfunction, prognosis

\section{Introduction}

Brain natriuretic peptide (BNP) is a 32-amino acid peptide which functions as a cardiac neurohormone that is predominantly released from the cardiac ventricle in response to left ventricular (LV) volume expansion and pressure overload (1). As such, BNP is a potent vasodilator and a natriuretic factor that regulates salt and water homeostasis. Increased secretion of BNP predominantly occurs in response to increased tension in the ventricular walls, decreased oxygen supply, acute myocardial infarction (MI), chronic cardiac heart failure (HF) and during hypertrophy of the heart (2). It has previously been demonstrated that BNP levels are useful for the diagnosis of LV systolic and diastolic dysfunction, and these levels correlate with the severity and prognosis of the dysfunction (3). As $\mathrm{BNP}$ is predominantly released from the LV myocardium, it is necessary to measure the regional function of the sympathetic nervous system in the left ventricle in order to elucidate the mechanisms associated with the release of BNP release and the clinical significance of the increased BNP levels during HF (4).

The prognostic importance of BNP and the N-terminal of pro (NT-pro)BNP has previously been investigated in patients with acute coronary syndromes and patients with $\mathrm{HF}$, and both markers were shown to be strong predictors of mortality and morbidity (5). In particular, diastolic wall stress has been demonstrated to have a stronger correlation with NT-proBNP levels, as compared with systolic wall stress (6). Previous studies have suggested that the estimation of BNP values via a fast and reliable blood test may be accepted as a diagnostic tool for assessing asymptomatic diastolic dysfunction in patients with hypertrophic cardiomyopathy (HCM), diabetes and hypertension (7-9). Furthermore, as BNP has been demonstrated to be a highly useful, simple and noninvasive diagnostic biomarker, BNP levels may be used for the differential diagnosis of cardiac and pulmonary dyspnea in emergency departments to guide therapy (10). However, whether BNP levels are predictors of morbidity and mortality in patients with diastolic dysfunction is yet to be investigated. Therefore, the present observational study aimed to elucidate the effects of BNP levels on the survival time of patients with diastolic dysfunction by grouping and following up 708 inpatients with cardiovascular disease until endpoint events occurred. 


\section{Materials and methods}

Ethics statement. The data collection in the present study was conducted according to the principles of the Declaration of Helsinki (https://en.wikipedia.org/wiki/Declaration_of_ Helsinki), and this process did not affect the normal course of therapy. All data were analyzed anonymously. The protocol of the present study was approved by the Ethics committee of the hospital, and written informed consent was obtained from each patient.

Subjects and procedures. In the present observational study, 708 inpatients with cardiovascular disease at the Division of Cardiology (Jinshan Hospital of Fudan University) were followed-up between May 2006 and December 2008 until endpoints occurred. The duration of follow-up ranged between 20 and 51 months and averaged 30.86 months. The mean age of patients was 66 years, and the majority of the patients were male $(395 / 708 ; 55.8 \%)$. Patients were classified according to an initial BNP cut-off point of $80 \mathrm{pg} / \mathrm{ml}$. Endpoints were defined as mortality or readmission due to cardiovascular disease, or mortality due to any other reason.

Measurement of plasma BNP concentration. Blood samples for the analysis of plasma BNP levels were harvested from the antecubital vein upon patient admission. BNP levels were analyzed using the Triage ${ }^{\circledR}$ BNP Test (Biosite Diagnostics, Inc., San Diego, CA, USA), which is a single-use fluorescence immunoassay device that is designed to determine BNP levels in ethylenediaminetetraacetic acid-anticoagulated whole blood or plasma specimens (EDTA purchased from Biosite Diagnostics, Inc.). Briefly, the specimen was added to the sample port of the test device using a $250-\mu \mathrm{l}$ transfer pipette and the device was inserted into the Triage ${ }^{\circledR}$ meter (Biosite Diagnostics, Inc.). BNP analysis was automatically conducted after the sample had reacted with the reagents within the BNP device. Reaction and analysis lasted $\sim 15 \mathrm{~min}$. BNP quantification was conducted based on the quantity of fluorescence detected by the meter within the measurement zone on the device, where increased fluorescence indicated a higher concentration of BNP in the specimen (11).

Echocardiography. M-mode and two-dimensional images, and color flow Doppler recordings were obtained using Vivid-7 ultrasound system (GE Healthcare Bio-Sciences, Pittsburgh, PA, USA ) operating at $2.0-3.5 \mathrm{MHz}$, as previously described (11). LV ejection fraction (LVEF) was calculated according to the Simpson formula outlined by Teichholz et al (12). In the present study, LVEF $\geq 50 \%$ indicated that LV systolic function was normal, whereas LVEF $<50 \%$ indicated systolic dysfunction. A $7.5 \mathrm{MHz}$ pulsed Doppler transducer (GE Healthcare Bio-Sciences) was used to measure diastolic transmitral Doppler parameters, including the peaks of early (E) and late diastolic (A) mitral flow velocities. Diastolic dysfunction was defined as an E/A ratio $\leq 1$.

Statistical analysis. Baseline characteristics of patients enrolled in the present were presented as percentages and medians with interquartile ranges for dichotomous and continuous variables, respectively. Between-group baseline characteristics comparisons were performed using Wilcoxon rank-sum test and the $\chi^{2}$ test for continuous and variables discrete, respectively. Survival curves were generated using Kaplan-Meier estimates; between-group differences in survival duration were compared using the log-rank test. Between-groups differences in the incidence of endpoint events were evaluated via relative risk (RR).

Spearman correlation was used to correlate continuous data with BNP levels and the duration of patients survival. BNP levels were evaluated via receiver operating characteristic (ROC) and area under curve (AUC) analyses for the prediction of clinical endpoints. In order to determine optimal specificity $(\mathrm{Sp})$ and sensitivity (Se) values the value closest to the peak $\mathrm{Sp}$ and Se points on the ROC curve was identified. $\mathrm{P}<0.05$ was considered to indicate a statistically significant difference.

\section{Results}

Clinical characteristics. The baseline clinical characteristics of the patient population investigated in the present study are shown in Table I. Patient risk factors included: Hypertension $(\mathrm{n}=390 ; 55 \%)$; diabetes $(\mathrm{n}=147 ; 21 \%)$; hyperlipidemia $(\mathrm{n}=101$; $14 \%$ ); renal dysfunction, which was defined by serum creatinine $>84$ or $>104 \mu \mathrm{mol} / 1$ in females and males, respectively ( $\mathrm{n}=115 ; 16 \%)$; MI ( $\mathrm{n}=90 ; 13 \%)$; and pharmacological intervention, including treatment with $\beta$-blockers, calcium antagonists, diuretics, nitrates, antiplatelet agents, statins, angiotensin converting enzyme inhibitor and angiotensin receptor blocker. A total of 415 and 293 patients exhibited BNP $\leq 80$ and $>80 \mathrm{pg} / \mathrm{ml}$, respectively. During follow-up, 144 endpoint events occurred, including 67 and 77 in the $\mathrm{BNP} \leq 80 \mathrm{pg} / \mathrm{ml}$ and $>80 \mathrm{pg} / \mathrm{ml}$ groups, respectively. Among the two patient groups, mortality and readmission rates were $32(4.5 \%)$ and $112(15.8 \%)$, respectively. Mortality rates were significantly higher in the BNP $>80 \mathrm{pg} / \mathrm{ml}$ group, as compared with the $\mathrm{BNP} \leq 80 \mathrm{pg} / \mathrm{ml}$ group $(\mathrm{P}<0.05)$; whereas readmission was markedly elevated in the BNP $\leq 80 \mathrm{pg} / \mathrm{ml}$ group, as compared with the BNP $>80 \mathrm{pg} / \mathrm{ml}$ group. A total of 677 patients underwent echocardiograph detection at the same time, including 499 (73.7\%) patients with diastolic dysfunction and 277 (40.9\%) patients with systolic dysfunction. The incidence of endpoint events was significantly elevated in the BNP $>80 \mathrm{pg} / \mathrm{ml}$, as compared with the BNP $\leq 80 \mathrm{pg} / \mathrm{ml}$ group (26.28 vs. $16.14 \% ; \mathrm{RR}=1.63)$.

Patient survival times decrease as BNP levels increase. Kaplan-Meier analysis survival curves of patients grouped according to initial BNP levels are shown in Fig. 1. This analysis was performed in order to investigate whether the survival time of patients in the $\mathrm{BNP} \leq 80 \mathrm{pg} / \mathrm{ml}$ group was increased compared with patients in the BNP $>80 \mathrm{pg} / \mathrm{ml}$ group. The results demonstrated that patients in the BNP $\leq 80 \mathrm{pg} / \mathrm{ml}$ group survived significantly longer, as compared with the $\mathrm{BNP}>80 \mathrm{pg} / \mathrm{ml}$ group $(\mathrm{P}=0.0006$; log rank=11.74).

Spearman correlation analysis demonstrated that the survival time of the 708 patients enrolled in the present study markedly decreased as BNP levels increased (Spearman's rho=-0.1006; $\mathrm{P}=0.0074)$. This negative correlation between the $\log$ BNP levels and survival time is shown in Fig. 2. No significant correlation was detected between BNP 
Table I. Baseline clinical characteristics of patients grouped according to BNP level.

\begin{tabular}{|c|c|c|c|}
\hline Parameter & $\mathrm{BNP} \leq 80 \mathrm{pg} / \mathrm{ml}(\%)$ & $\mathrm{BNP}>80 \mathrm{pg} / \mathrm{ml}(\%)$ & P-value \\
\hline Patients (n) & 415 & 293 & - \\
\hline Age (years) & $62(54-72)$ & $74(64-78.75)$ & $<0.05$ \\
\hline Male (\%) & $226(54)$ & $169(57)$ & 0.395 \\
\hline Mortality (\%) & $3(0.72)$ & $29(9.90)$ & $<0.05$ \\
\hline Readmission (\%) & $64(15.42)$ & $48(16.38)$ & 0.73 \\
\hline Endpoint events & $67(16.14)$ & $77(26.28)$ & 0.001 \\
\hline Diastolic dysfunction & 297/397 (74.81) & 202/280 (72.14) & 0.451 \\
\hline Systolic dysfunction & $112 / 397(28.21)$ & $165 / 280(58.93)$ & $<0.05$ \\
\hline Hypertension & $208(50.12)$ & $182(62.12)$ & 0.002 \\
\hline Diabetes & 77 (18.55) & $70(23.89)$ & 0.085 \\
\hline Hyperlipidemia & $74(17.83)$ & $27(9.22)$ & 0.001 \\
\hline Renal failure & $29(6.99)$ & $86(29.35)$ & $<0.05$ \\
\hline Myocardial infarction & $43(10.36)$ & $47(16.04)$ & 0.025 \\
\hline \multicolumn{4}{|l|}{ Medications: } \\
\hline$\beta$-blockers & $245(59.04)$ & $148(50.51)$ & 0.025 \\
\hline Calcium antagonists & $139(33.49)$ & 99 (33.79) & 0.935 \\
\hline Diuretic & $126(30.36)$ & $230(78.50)$ & $<0.05$ \\
\hline Nitrates & $214(51.57)$ & $141(48.12)$ & 0.367 \\
\hline Antiplatelet agents & $328(79.04)$ & $217(74.06)$ & 0.121 \\
\hline Statins & $118(28.43)$ & 79 (26.96) & 0.667 \\
\hline ACEI or ARB & $323(77.83)$ & $239(81.57)$ & 0.226 \\
\hline ACEI & $168(40.48)$ & $127(43.34)$ & 0.447 \\
\hline $\mathrm{ARB}$ & $155(37.35)$ & $112(38.23)$ & 0.813 \\
\hline
\end{tabular}

BNP, brain natriuretic peptide; ACE, angiotensin converting enzyme inhibitor; ARB, angiotensin receptor blocker. Wilcoxon rank-sum test and the $\chi^{2}$ test was used.

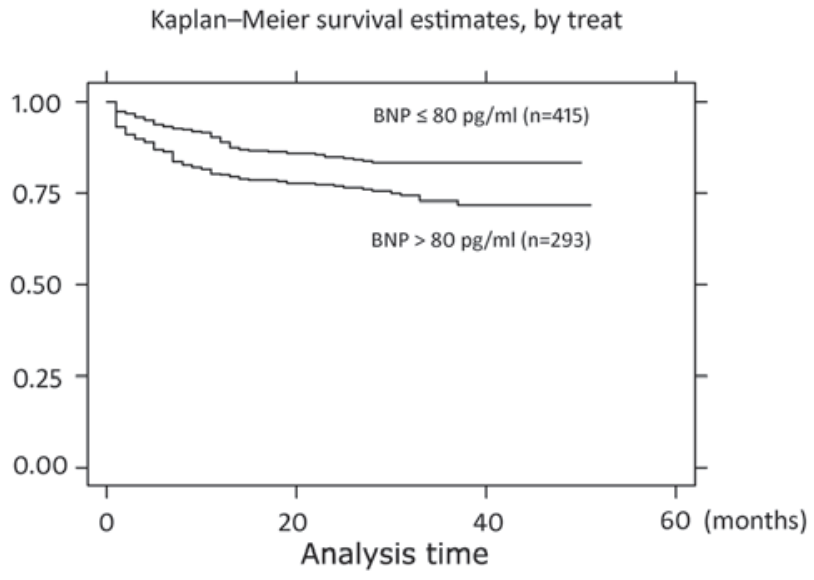

Figure 1. Kaplan-Meier survival analysis of the patients with plasma BNP levels higher and lower than the $80 \mathrm{pg} / \mathrm{ml}$ cut-off value. $\mathrm{P}=0.0006 ; \log$ rank=11.74. BNP, brain natriuretic peptide.

levels and survival time in the 178 patients with normal LV diastolic function (Spearman's rho=-0.931; $\mathrm{P}=0.2165$ ) and 277 patients with systolic dysfunction (Spearman's rho=-0.0007; $\mathrm{P}=0.9904)^{\prime}$ whereas a negative correlation was detected in the 499 patients with LV diastolic dysfunction $(\mathrm{E} / \mathrm{A} \leq 1)($ Spearman's rho=-0.0899; $\mathrm{P}=0.0447)$. A scatter plot

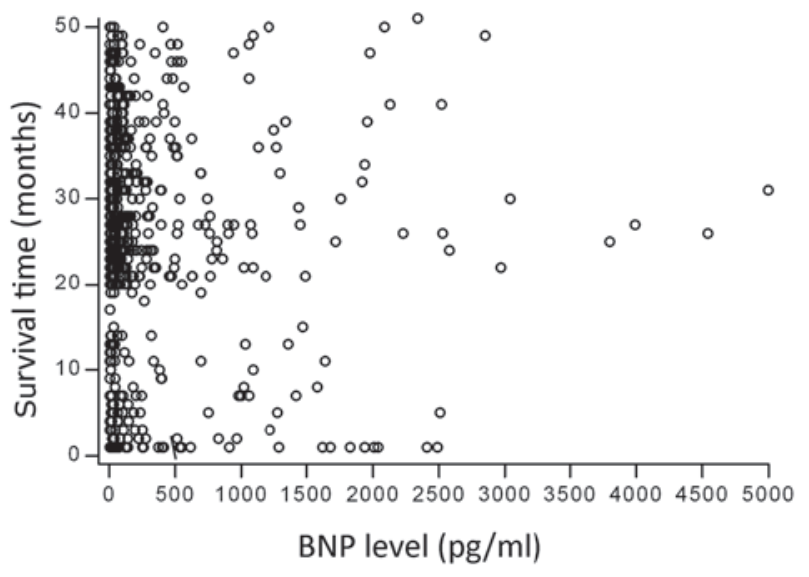

Figure 2. Scatter plots demonstrating the correlation between log BNP levels and survival time in all patients $(n=708)$. BNP, brain natriuretic peptide.

demonstrating the correlation between the log BNP level and duration of survival in patients with diastolic dysfunction are shown in Fig. 3.

BNP levels can predict clinical endpoints in patients with diastolic dysfunction. The predictive utility of plasma BNP 
Table II. Correlation between the log BNP level and endpoint events in all patients.

\begin{tabular}{lccc}
\hline & \multicolumn{2}{c}{ Endpoint events } & \\
\cline { 2 - 3 } BNP level & Yes & No & Total \\
\hline$>80 \mathrm{pg} / \mathrm{ml}$ & 77 & 216 & 293 \\
$\leqq 80 \mathrm{pg} / \mathrm{ml}$ & 67 & 348 & 415 \\
Total & 144 & 564 & 708 \\
\hline
\end{tabular}

The $\chi^{2}$ test was used. BNP, brain natriuretic peptide.

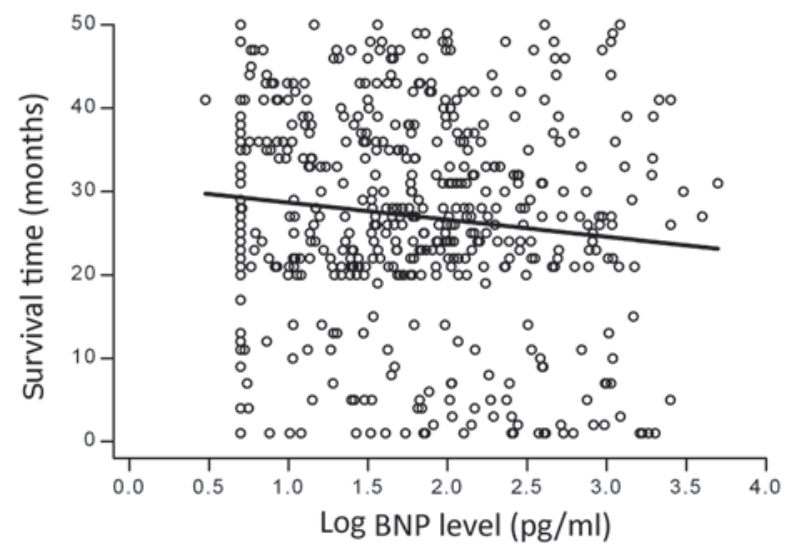

Figure 3. Scatter plots demonstrating the correlation between log BNP levels and survival time in patients with diastolic dysfunction $(n=499)$. BNP, brain natriuretic peptide.

levels for the determination of compound clinical endpoints was calculated via ROC analysis in all patients. The area under the ROC curve was 0.6127 [standard error $(\mathrm{SE})=0.0268$; 95\% confidence interval (CI) 0.56015-0.66531]. The cut-off value of the plasma BNP level was $80 \mathrm{pg} / \mathrm{ml}$ (Se, 53.47\%; Sp, 61.7\%) (Fig. 4 and Table II). In patients with diastolic dysfunction, the area under the ROC curve was 0.5977 ( $\mathrm{SE}=0.0345 ; 95 \% \mathrm{CI}, 0.53020-0.66524)$. In this group, the cut-off value of the plasma BNP level was $80 \mathrm{pg} / \mathrm{ml}$ (Se, $52.17 \%$; Sp, 62.16\%) (Fig. 5 and Table III). No significant correlation was detected between plasma BNP levels and the incidence of endpoint events in patients with systolic dysfunction.

\section{Discussion}

BNP is a cardiac neurohormone secreted from the ventricles into the plasma in response to ventricular volume expansion and pressure overload (3). It has previously been demonstrated that the determination of BNP levels provides a straightforward method for the early detection of HF, the assessment of HF severity and the effectiveness of treatment (13). A previous study (14) has shown that both BNP and NT-proBNP are strong prognostic markers for numerous acute coronary syndromes, including patients with unstable angina, non-ST and ST-elevation MI (15-17) and stable angina pectoris $(18,19)$. In the absence of significant necrosis $(20)$, BNP and NT-proBNP are present in human coronary
Table III. Correlation between the log BNP level and endpoint events in patients with diastolic dysfunction.

\begin{tabular}{llll}
\hline & \multicolumn{2}{c}{ Endpoint events } & \\
\cline { 2 - 3 } BNP level & Yes & No & Total \\
\hline$>80 \mathrm{pg} / \mathrm{ml}$ & 48 & 154 & 202 \\
$\leqq 80 \mathrm{pg} / \mathrm{ml}$ & 44 & 253 & 297 \\
Total & 92 & 407 & 499 \\
\hline
\end{tabular}

The $\chi^{2}$ test was used. BNP, brain natriuretic peptide.

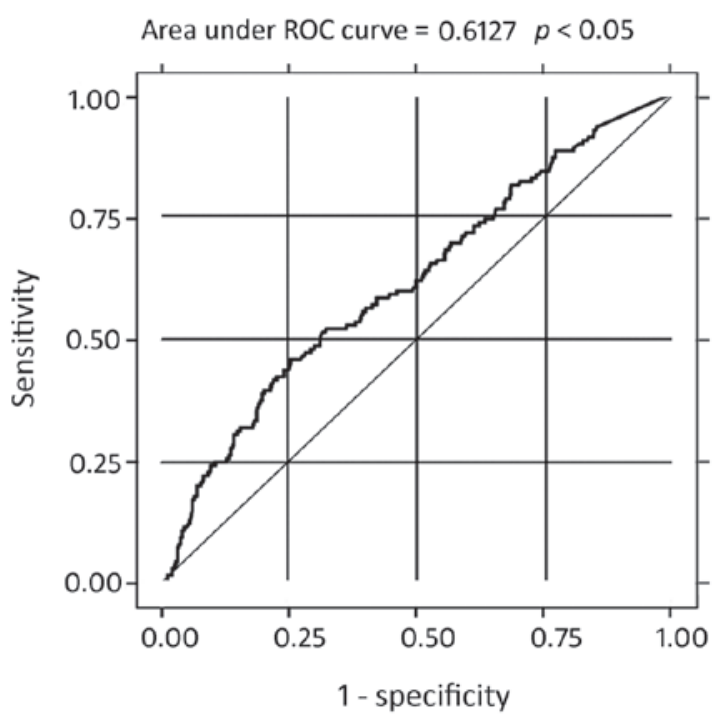

Figure 4. ROC analysis of log brain natriuretic peptide levels for determining compound clinical endpoint events in all patients $(n=708)$. Area under the curve $=0.6127$ and standard error $=0.0268$ (95\% confidence interval, $0.56015-0.66531)$. The cut-off value was determined to be $80 \mathrm{pg} / \mathrm{ml}$ (specificity, 61.7\%; sensitivity, 53.47\%). ROC, receiver operating characteristic.

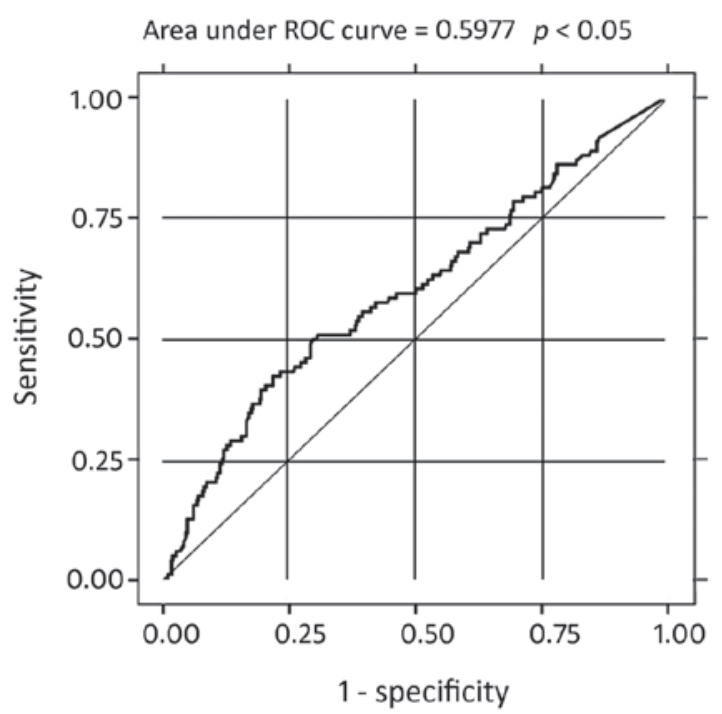

Figure 5. ROC analysis of log brain natriuretic peptide levels for determining compound clinical endpoint events in patients with diastolic dysfunction $(n=499)$. Area under the curve $=0.5977$ and standard error $=0.0345(95 \%$ confidence interval, $0.53020-0.66524)$. The cut-off value was determined to be $80 \mathrm{pg} / \mathrm{ml}$ (specificity, 62.16\%; sensitivity, 52.17\%). ROC, receiver operating characteristic. 
arteries (21) and are associated with the extent and severity of coronary atherosclerotic lesions (22). The results of the present study were consistent with these previous findings; the number of patients who suffered a MI was significantly elevated in the BNP $>80 \mathrm{pg} / \mathrm{ml}$ group, as compared with the $\mathrm{BNP} \leq 80 \mathrm{pg} / \mathrm{ml}$ group $(\mathrm{P}=0.025)$. It has previously been suggested that ischemia may act as a stimulus for the release of BNP and NT-proBNP (23). Sympathetic nervous overactivity in the left ventricle has been demonstrated to be an important mechanism for the induction of BNP elevation in chronic ischemic HF (4). Furthermore, previous studies have shown that ventricular BNP gene expression is upregulated by acute myocardial hypoxia, which results in increased plasma BNP and proBNP levels $(24,25)$.

NT-proBNP is independent of invasive measurements of LV function and the severity of coronary artery disease (19). Previous studies have investigated the prognostic importance of measuring BNP and NT-proBNP levels in patients with $\mathrm{HF}$ and acute coronary syndromes, and both markers were demonstrated to be strong and independent predictors of morbidity and mortality $(19,26,27)$. These predictors were also detected in $>60 \%$ of the subgroup of patients with LV ejection fraction and in patients with diabetes mellitus (28). Kragelund et al (19) demonstrated that, when measured immediately prior to coronary angiography, NT-proBNP provides prognostic information on mortality in patients with stable coronary heart disease (19). The results of the present study were consistent with these findings and suggest that BNP demonstrates the same prognostic value as previous studies. The incidence of clinical endpoints, which included mortality or readmission due to cardiovascular disease, or mortality due to any other reason, was significantly higher in the BNP $>80 \mathrm{pg} / \mathrm{ml}$ group, as compared with the BNP $\leq 80 \mathrm{pg} / \mathrm{ml}$ group. Furthermore, Kaplan-Meier analysis survival curves suggested a negative correlation between the log BNP level and survival duration in patients with cardiovascular disease. Patients in the BNP $\leq 80 \mathrm{pg} / \mathrm{ml}$ group survived significantly longer, as compared with the $\mathrm{BNP}>80 \mathrm{pg} / \mathrm{ml}$ group $(\mathrm{P}=0.0006$, $\log$ rank=11.74); therefore, survival duration reduced as $\mathrm{BNP}$ levels increased.

In the present study, a cut-off value of $80 \mathrm{pg} / \mathrm{ml}$ plasma BNP was used for the prediction of cardiovascular morbidity and mortality from all death causes, including cardiovascular diseases (Se, 53.47\%; Sp, 61.7\%). BNP or NT-proBNP have previously been shown to have a high negative predictive value as a single test (29), and the results of the present study were consistent with these findings. The present study assessed inpatients with various diseases, including, but not limited to, hypertension, diabetes, hyperlipidemia, renal failure and MI, between May 2006 and December 2008 at the Division of Cardiology (Jinshan Hospital of Fudan University). The results demonstrated that BNP levels may be used for the prediction of various cardiovascular diseases, rather than one or several specific diseases. Therefore, the present study demonstrated the wider application of BNP as a predictor, as compared with previous studies (7-9).

A previous study has demonstrated that $40-50 \%$ of individuals with HF have a normal ejection fraction, and diastolic dysfunction is the presumed cause of diastolic HF (DHF) (30). Abnormalities in diastolic function are often misdiagnosed as this condition does not always produce signs and symptoms of $\mathrm{HF}$, which leaves patients predisposed to symptomatic HF and cardiac necrosis due to the delay in treatment (31). The early diagnosis of LV diastolic dysfunction during its initial phase facilitates the initiation of effective treatment with the purpose of halting the progress of the disease and delaying the development of symptomatic HF (32). Echocardiography, using both Doppler measurements of transmitral and pulmonary vein blood flow velocities and tissue Doppler imaging, is a widely accepted method for the clinical analysis of diastole (33). However, these assessments are: i) Costly due to the requirement of complex equipment; ii) time-consuming, as they involves the analysis of various variables; and iii) difficult, therefore they must be performed by a trained operator (34). Therefore, a simple, objective, high sensitivity and high specificity method for the evaluation of diastole function is required. An association between BNP levels and the indices of diastolic function has previously been described in patients with reduced and preserved LVEF (35). Previous studies have demonstrated that the estimation of BNP values provides a fast and reliable blood test in the diagnosis of asymptomatic diastolic dysfunction $(7,8)$. In particular, the BNP test has previously been evaluated for the prediction of asymptomatic diastolic dysfunction in patients with hypertension (7); and BNP levels may be determined in order to evaluate occult LV dysfunction in patients who are periodically assessed for diabetic complications (8). Furthermore, Panou et al (9) have demonstrated that BNP assessment may be used as an adjunctive, reliable and objective way of estimating cardiac dysfunction in HCM (9). These findings were supported by a subsequent study that demonstrated that assessment of BNP levels can be easily and rapidly performed in emergency departments to guide therapy, follow the response to therapy and predict the exercise capacity of patients (10). The results of the present study indicated that patients with elevated BNP levels suffered poorer prognoses, as compared with those with lower BNP levels. A negative correlation between BNP levels and survival time was detected in patients with LV diastolic dysfunction $(n=499)$, and survival time decreased as BNP levels rose. Furthermore, the predictive utility of plasma BNP levels for the determination of compound clinical endpoints was demonstrated in patients with diastolic dysfunction. In patients with diastolic dysfunction enrolled in the present study, morbidity and mortality associated with cardiovascular diseases were increased in patients with elevated plasma BNP levels, as compared with patients with lower BNP levels. In patients with systolic dysfunction, no significant correlation or predictive value was detected between plasma BNP levels and survival time and morbidity and mortality from cardiovascular diseases.

The findings of the present study are consistent with a previous study which has suggested that diastolic wall stress may have a stronger correlation with NT-proBNP levels, as compared with systolic wall stress (6). In a previous study, BNP levels exhibited higher sensitivity (85 vs. 63\%) and positive predictive values (69 vs. 55\%), as compared with the assessment of NT-proBNP levels; although the negative predictive values of BNP and NT-proBNP remained similar (70 and 71\%, respectively) (36). Furthermore, measuring BNP levels has been demonstrated to have a higher sensitivity and 
positive predictive value for the accurate diagnosis of severe LVSD, as compared with measuring NT-proBNP levels (36). The plasma half-life of BNP in humans is $\sim 20 \mathrm{~min}$, whereas the circulating half-life of NT-proBNP is $\sim 120 \mathrm{~min}$ (37). Therefore, BNP level determination may facilitate assessment of the current severity of LV dysfunction, guide therapy and track the immediate response to therapy, whereas the use of NT-proBNP levels for assessment would lag by $\sim 10 \mathrm{~h}$. Clearance of BNP occurs via two main mechanisms: i) Binding to clearance receptors; and ii) enzymatic degradation by neutral endopeptidase (38). Clearance of NT-proBNP predominantly occurs via the kidney and NT-proBNP levels significantly rise during mild renal failure, which seriously affects the utility of NT-proBNP for diagnosis $(39,40)$, as $29 \%$ of patients with HF suffer from renal failure (41). In patients aged $\geq 65$, the BNP assay is a more useful diagnostic indicator for cardiogenic pulmonary edema, as compared with proBNP (39). The estimated glomerular filtration rate has independent effects upon plasma BNP and NT-proBNP concentrations in patients with chronic kidney disease, and NT-proBNP appears to be more severely affected by declining kidney function (42). Therefore, based on these findings and the results of the present study, the use of plasma BNP levels may result in a reliable and effective assessment of prognosis in patients with cardiovascular diseases.

The present study had several limitations. Firstly, the number of patients enrolled in the study was small and the follow-up period was relatively short. Therefore, future studies with a larger sample of patients should be conducted over a longer period in order to assess the predictive value of BNP in patients with cardiovascular-related disease, particularly patients with LV diastolic dysfunction. Secondly, echocardiographic parameters should be interpreted with caution as the E/A may be affected by rapid ventricular rate and atrial fibrillation. Thirdly, the sensitivity and specificity of the predictive utility of plasma BNP levels for the determination of compound clinical endpoints in all patients or patients with LV diastolic dysfunction was not particularly high. In a previous study, the combination of NT-proBNP or BNP with LVEF substantially improved the risk stratification for mortality, HF, and new ischemic events (43).

In conclusion, the prognoses of patients with elevated BNP levels were correspondingly worse when compared with patients with lower BNP levels. This correlation was demonstrated to be significant in patients with LV diastolic dysfunction. Therefore, the results of the present study suggested that BNP levels may be used to predict the prognosis of patients with cardiovascular disease, particularly in patients with LV diastolic dysfunction.

\section{Acknowledgements}

We would like to thank Miss Feng-Ping Zhu for data collection and Dr Lei-Jun Huang from Echo Laboratory for the measurements of cardiographs.

\section{References}

1. Epshteyn V, Morrison K, Krishnaswamy P, Kazanegra R, Clopton P, Mudaliar S, Edelman S, Henry R and Maisel A: Utility of B-type natriuretic peptide (BNP) as a screen for left ventricular dysfunction in patients with diabetes. Diabetes Care 26: 2081-2087, 2003.
2. Magnusson M, Melander O, Israelsson B, Grubb A, Groop L and Jovinge S: Elevated plasma levels of NT-proBNP in patients with type 2 diabetes without overt cardiovascular disease. Diabetes Care 27: 1929-1935, 2004.

3. Kremastinos DT, Tsiapras DP, Kostopoulou AG, Hamodraka ES, Chaidaroglou AS and Kapsali ED: NT-proBNP levels and diastolic dysfunction in beta-thalassaemia major patients. Eur J Heart Fail 9: 531-536, 2007.

4. Sakata K, Iida K, Mochiduki N and Nakaya Y: Brain natriuretic peptide (BNP) level is closely related to the extent of left ventricular sympathetic overactivity in chronic ischemic heart failure. Inter Med 48: 393-400, 2009.

5. McKie PM, Rodeheffer RJ, Cataliotti A, Martin FL, Urban LH, Mahoney DW, Jacobsen SJ, Redfield MM and Burnett JC Jr: Amino-terminal proB-type natriuretic peptide and B-type natriuretic peptide: Biomarkers for mortality in a large community-based cohort free of heart failure. Hypertension 47 : 874-880, 2006.

6. Krittayaphong R, Boonyasirinant T, Saiviroonporn P, Thanapiboonpol P, Nakyen S and Udompunturak S: Correlation between NT-pro BNP levels and left ventricular wall stress, sphericity index and extent of myocardial damage: A magnetic resonance imaging study. J Card Fail 14: 687-694, 2008.

7. Karaca I, Gülcü E, Yavuzkir M, Dağli N, Ilkay E, Ozbay Y, Işik A and Arslan N: B-type natriuretic peptide level in the diagnosis of asymptomatic diastolic dysfunction. Anadolu Kardiyol Derg 7: 262-267, 2007.

8. Kremastinos DT, Hamodraka E, Parissis J, Tsiapras D, Dima K and Maisel A: Predictive value of B-type natriuretic peptides in detecting latent left ventricular diastolic dysfunction in beta-thalassemia major. Am Heart J 159: 68-74, 2010.

9. Panou FK, Kotseroglou VK, Lakoumentas JA, Chrysanthopoulou SA, Armeniakos JA, Stratigou T, Veve H and Zacharoulis AA: Significance of brain natriuretic peptide in the evaluation of symptoms and the degree of left ventricular diastolic dysfunction in patients with hypertrophic cardiomyopathy. Hellenic J Cardiol 47: 344-351, 2006.

10. Eroglu S, Yildirir A, Bozbas H, Aydinalp A, Ulubay G, Eldem O, Simsek V, Ozin B and Muderrisoglu H: Brain natriuretic peptide levels and cardiac functional cpacity in patients with dyspnea and isolated diastolic dysfunction. Int Heart J 48: 97-106, 2007.

11. Gong H, Wang X, Ling Y, Shi Y and Shi H: Prognostic value of brain natriuretic peptide in patients with heart failure and reserved left ventricular systolic function. Exp Ther Med 7: 1506-1512, 2014.

12. Teichholz LE, Kreulen T, Herman MV and Gorlin R: Problems in echocardiographic volume determinations: Echocardiographic-angiographic correlations in the presence of absence of asynergy. Am J Cardiol 37: 7-11, 1976.

13. He Q, Wu G and Lapointe MC: Isoproterenol and cAMP regulation of the human brain natriuretic peptide gene involves Src and Rac. Am J Physiol Endocrinol Metab 278: E1115-E1123, 2000.

14. Suo M, Hautala N, Földes G, Szokodi I, Tóth M, Leskinen H, Uusimaa P, Vuolteenaho O, Nemer $M$ and Ruskoaho $H$ : Posttranscriptional control of BNP gene expression in angiotensin II-induced hypertension. Hypertension 39: 803-808, 2002.

15. James SK, Lindahl B, Siegbahn A, Stridsberg M, Venge P, Armstrong P, Barnathan ES, Califf R, Topol EJ, Simoons ML and Wallentin L: N-terminal pro-brain natriuretic peptide and other risk markers for the separate prediction of mortality and subsequent myocardial infarction in patients with unstable coronary artery disease: A global utilization of strategies to open occluded arreries (GUSTO)-IV substudy. Circulation 108: 275-281, 2003.

16. Morrow DA, de Lemos JA, Blazing MA, Sabatine MS, Murphy SA, Jarolim P, White HD, Fox KA, Califf RM and Braunwald E; Investigators: Prognostic value of serial B-type natriuretic peptide testing during follow-up of patients with unstable coronary artery disease. JAMA 294: 2866-2871, 2005.

17. Morrow DA, de Lemos JA, Sabatine MS, Murphy SA, Demopoulos LA, DiBattiste PM, McCabe CH, Gibson CM, Cannon CP and Braunwald E: Evaluation of B-type natriuretic peptide for risk assessment in unstable angina/non-ST-elevation myocardial infarction: B-type natriuretic peptide and prognosis in TACTICS-TIMI 18. J Am Coll Cardiol 41: 1264-1272, 2003.

18. Ceriani L and Giovanella L: Cardiac natriuretic peptides after myocardial infarction: Relationship with infarct size, left ventricular function and remodelling assessed by $99 \mathrm{mTc}$-sestamibi gated-single photon emission tomography. Clin Chem Lab Med 45: 226-231, 2007. 
19. Kragelund C, Grønning B, Køber L, Hildebrandt $\mathrm{P}$ and Steffensen R: N-terminal pro-B-type natriuretic peptide and long-term mortality in stable coronary heart disease. N Engl J Med 352: 666-675, 2005.

20. Barbosa MM, Nunes Mdo C, Castro LR, Nominato LF, Alencar MC and Ribeiro AL: Correlation between NT-pro BNP levels and early mitral annulus velocity (E') in patients with non-ST-segment elevation acute coronary syndrome. Echocardiography 25: 353-359, 2008.

21. Casco VH, Veinot JP, Kuroski de Bold ML, Masters RG, Stevenson MM and de Bold AJ: Natriuretic peptide system gene expression in human coronary arteries. J Histochem Cytochem 50: 799-809, 2002.

22. Weber M, Dill T, Arnold R, Rau M, Ekinci O, Müller KD, Berkovitsch A, Mitrovic V and Hamm C: N-terminal B-type natriuretic peptide predicts extent of coronary artery disease and ischemia in patients with stable angina pectoris. Am Heart J 148: 612-620, 2004

23. Omland T: B-type natriuretic peptides: Prognostic markers in stable coronary artery disease. Expert Rev Mol Diagn 8: 217-225, 2008.

24. Goetze JP, Christoffersen C, Perko M, Arendrup H, Rehfeld JF, Kastrup J and Nielsen LB: Increased cardiac BNP expression associated with myocardial ischemia. FASEB J 17: 1105-1107, 2003 .

25. Goetze JP, Gore A, Møller CH, Steinbrüchel DA, Rehfeld JF and Nielsen LB: Acute myocardial hypoxia increases BNP gene expression. FASEB J 18: 1928-1930, 2004.

26. Omland T, Persson A, Ng L, O'Brien R, Karlsson T, Herlitz J, Hartford $\mathrm{M}$ and Caidahl K: N-terminal pro-B-type natriuretic peptide and long-term mortality in acute coronary syndromes. Circulation 106: 2913-2918, 2002

27. de Lemos JA, Morrow DA, Bentley JH, Omland T, Sabatine MS McCabe $\mathrm{CH}$, Hall C, Cannon $\mathrm{CP}$ and Braunwald E: The prognostic value of B-type natriuretic peptide in patients with acute coronary syndromes. N Engl J Med 345: 1014-1021, 2001.

28. Kragelund C, Gustafsson I, Omland T, Grønning B, Køber L, Faber J, Strande S, Steffensen R and Hildebrandt P: Prognostic value of $\mathrm{NH} 2$-terminal proB-type natriuretic peptide in patients with diabetes and stable coronary heart disease. Diabetes Care 29: 1411-1413, 2006

29. Kelder JC, Rutten FH and Hoes AW: Clinically relevant diagnostic research in primary care: The example of B-type natriuretic peptides in the detection of heart failure. Fam Pract 26: 69-74, 2009.

30. Redfield MM, Jacobsen SJ, Burnett JC Jr, Mahoney DW, Bailey KR and Rodeheffer RJ: Burden of systolic and diastolic ventricular dysfunction in the community: Appreciating the scope of the heart failure epidemic. JAMA 289: 194-202, 2003.

31. Shimabukuro M, Higa N, Oshiro Y, Asahi T and Takasu N: Diagnostic utility of brain-natriuretic peptide for left ventricular diastolic dysfunction in asymptomatic type 2 diabetic patients. Diabetes Obes Metabo 9: 323-329, 2007.
32. Görmüs U, Ozmen D, Ozmen B, Parildar Z, Ozdoğan O, Mutaf I and Bayindir O: Serum N-terminal-pro-brain natriuretic peptide (NT-pro-BNP) and homocysteine levels in type 2 diabetic patients with asymptomatic left ventricular diastolic dysfunction. Diabetes Res Clin Pract 87: 51-56, 2010.

33. Metra M, Ponikowski P, Dickstein K, McMurray JJ, Gavazzi A, Bergh CH, Fraser AG, Jaarsma T, Pitsis A, Mohacsi P, et al: Advanced chronic heart failure: A position statement from the study group on advanced heart failure of the heart failure association of the european society of cardiology. Eur J Heart Fail 9: 684-694, 2007.

34. Nagueh SF, Appleton CP, Gillebert TC, Marino PN, Oh JK, Smiseth OA, Waggoner AD, Flachskampf FA, Pellikka PA and Evangelista A: Recommendations for the evaluation of left ventricular diastolic function by echocardiography. J Am Soc Echocardiogr 22: 107-133, 2009.

35. Grewal J, McKelvie R, Lonn E, Tait P, Carlsson J, Gianni M, Jarnert $\mathrm{C}$ and Persson H: BNP and NT-proBNP predict echocardiographic severity of diastolic dysfunction. Eur J Heart Fail 10: 252-259, 2008

36. Kotaska K, Popelova J, Tiserova M, Telekes P, Vrzanova M, Bronsky J, Halacova M, Kukacka J and Prusa R: NT-proBNP and BNP values in cardiac patients with different degree of left ventricular systolic dysfunction. Biomed Pap Med Fac Univ Palacky Olomouc Czech Repub 150: 125-130, 2006.

37. Mair J, Hammerer-Lercher A and Puschendorf B: The impact of cardiac natriuretic peptide determination on the diagnosis and management of heart failure. Clin Chem Lab Med 39: 571-588, 2001.

38. Ruskoaho H: Cardiac hormones as diagnostic tools in heart failure. Endor Rev 24: 341-356, 2003

39. Ray P, Arthaud M, Birolleau S, Isnard R, Lefort Y, Boddaert J and Riou B: Comparison of brain natriuretic peptide and probrain natriuretic peptide in the diagnosis of cardiogenic pulmonary edema in patients ages 65 and older. J Am Geriatr Soc 53: 643-648, 2005

40. Sykes E, Karcher RE, Eisenstadt J, Tushman DA, Balasubramaniam M, Gusway J and Perason VJ: Analytical relationships among Biosite, Bayer and Roche methods for BNP and NT-proBNP. Am J Clin Pathol 123: 584-590, 2005.

41. Fonarow GC and ADHERE Scientific Advisory Committee: The acute decompensated heart failure national registry (ADHERETM): Opportunities to improve care of patients hospitalized with acute decompensated heart failure. Rev Cardiovasc Med 4 (Suppl 7): S21-S30, 2003

42. Vickery S, Price CP, John RI, Abbas NA, Webb MC, Kempson ME and Lamb EJ: B-type natriuretic peptide (BNP) and amino-terminal proBNP in patients with CKD: Relationship to renal function and left ventricular hypertrophy. Am J Kidney Dis 46: 610-620, 2005.

43. Richards AM, Nicholls MG, Espiner EA, Lainchbury JG, Troughton RW, Elliott J, Frampton C, Turner J, Crozier IG and Yandle TG: B-type natriuretic peptides and ejection fraction for prognosis after myocardial infarction. Circulation 107: 2786-2792, 2003. 